OPEN ACCESS

Edited by:

Sara Marinelli,

Institute of Biochemistry and Cell

Biology (CNR), Italy

Reviewed by:

Arianna Scuteri,

University of Milano-Bicocca, Italy

Paul Fernyhough

University of Manitoba, Canada

${ }^{*}$ Correspondence:

Giorgia Moschetti

moschetti@ingm.org

Specialty section:

This article was submitted to

Multiple Sclerosis and

Neuroimmunology,

a section of the journal

Frontiers in Immunology

Received: 17 June 2020

Accepted: 05 August 2020

Published: 24 September 2020

Citation:

Moschetti G, Kalpachidou T, Amodeo G, Lattanzi R, Sacerdote P,

Kress $M$ and Franchi S (2020)

Prokineticin Receptor Inhibition With

PC1 Protects Mouse Primary Sensory

Neurons From Neurotoxic Effects of

Chemotherapeutic Drugs in vitro

Front. Immunol. 11:2119.

doi: 10.3389/fimmu.2020.02119

\section{Prokineticin Receptor Inhibition With PC1 Protects Mouse Primary Sensory Neurons From Neurotoxic Effects of Chemotherapeutic Drugs in vitro}

\author{
Giorgia Moschetti ${ }^{*}$, Theodora Kalpachidou ${ }^{2}$, Giada Amodeo ${ }^{1}$, Roberta Lattanzi ${ }^{3}$, \\ Paola Sacerdote ${ }^{1}$, Michaela Kress ${ }^{2}$ and Silvia Franchi ${ }^{1}$ \\ ${ }^{1}$ Department of Pharmacological and Biomolecular Sciences, Università Degli Studi di Milano, Milan, Italy, ${ }^{2}$ Department of \\ Physiology and Biomedical Physics, Medical University of Innsbruck, Innsbruck, Austria, ${ }^{3}$ Department of Physiology and \\ Pharmacology "Vittorio Erspamer", Sapienza University of Rome, Rome, Italy
}

Neurotoxicity is a common side effect of chemotherapeutics that often leads to the development of chemotherapy-induced peripheral neuropathy (CIPN). The peptide Prokineticin 2 (PK2) has a key role in experimental models of CIPN and can be considered an insult-inducible endangering mediator. Since primary afferent sensory neurons are highly sensitive to anticancer drugs, giving rise to dysesthesias, the aim of our study was to evaluate the alterations induced by vincristine (VCR) and bortezomib (BTZ) exposure in sensory neuron cultures and the possible preventive effect of blocking PK2 signaling. Both VCR and BTZ induced a concentration-dependent reduction of total neurite length that was prevented by the PK receptor antagonist PC1. Antagonizing the PK system also reduced the upregulation of PK2, PK-R1, TLR4, IL-6, and IL-10 expression induced by chemotherapeutic drugs. In conclusion, inhibition of PK signaling with $\mathrm{PC} 1$ prevented the neurotoxic effects of chemotherapeutics, suggesting a promising strategy for neuroprotective therapies against the sensory neuron damage induced by exposure to these drugs.

Keywords: chemotherapy, DRG, neurons, prokineticins, neurotoxicity

\section{INTRODUCTION}

Neurotoxicity is a common side effect of chemotherapeutic agents generally used in clinic for the treatment of cancer (1). Such neurotoxicity often leads to the development of chemotherapy-induced peripheral neuropathy (CIPN), which is one of the most common and debilitating dose-limiting side effects of first-line anticancer drugs (2-5). CIPN represents a complex syndrome characterized by many sensory abnormalities $(6,7)$, which make life difficult for patients that are already experiencing cancer. Neuropathy development has been associated with vinca alkaloids [e.g., vincristine (VCR)], proteasome inhibitors [e.g., bortezomib (BTZ)], platinum agents (e.g., oxaliplatin), and taxanes (e.g., paclitaxel) (8-11). Despite having different anti-tumoral mechanisms of action, all these drugs induce neuropathy both in humans and in experimental rodent models. Experimental painful peripheral neuropathies are already produced by relatively 
low doses that do not cause axonal degeneration in peripheral nerve. Partial degeneration of the intraepidermal innervation suggests mechanisms that might produce chemotherapy-evoked neuropathic pain, and activation of cutaneous Langerhans cells suggests possible neuroimmune interactions that might also have a role (12). Peripheral sensory neuron terminals appear to be particularly sensitive to damage induced by antineoplastic agents because of the lack of an efficient neurovascular barrier and the presence of a dense network of fenestrated capillaries, which lead to an unrestrained drug permeation $(3,13,14)$. Even if the molecular events underlying CIPN are still largely unknown, the involvement of mitochondrial toxicity, oxidative stress, ion channel alterations, and neuroinflammatory processes has been discussed $(4,13,15)$. Mammalian Prokineticin 2 (PK2) is a secreted bioactive peptide that belongs to the prokineticin (PK) family $(16,17)$ and has been shown to be involved not only in the onset but also in the persistence of painful conditions of several origins (18-22). PK2 is a ligand of two closely related G-protein-coupled receptors (GPCRs) known as PK-R1 and PK-R2 $(23,24)$. Both PK2 and its receptors are expressed in neurons and accessory cells (satellite cells, microglia, and astrocytes) in the nervous system and immune cells, such as granulocytes, macrophages, and lymphocytes (16, 25). In primary sensory afferents, PK 2 as well as PK-R1 and PK-R2 receptors are expressed in different neuron types: in dorsal root ganglia (DRG) harboring the cell bodies of primary afferent neurons, PK-R1 is mainly expressed on small-size nociceptors, while PK-R2 is expressed on medium- and largesized neurons $(25,26)$. PK2 receptor may couple to $\mathrm{Gq}, \mathrm{Gi}$, and Gs $(27,28)$ depending on their cellular localization and thus can activate different intracellular signaling pathways (16, 25). For example, in sensory neurons, PK2 receptors are Gqcoupled and promote intracellular $\mathrm{Ca}^{2+}$ mobilization through the activation of phospholipase C (PLC) and formation of IP3. PK2 receptor activation, via Gq, induces protein kinase C (PKC) $-\varepsilon$ translocation to the plasma membrane (29). PK2 sensitizes TRPV1- and TRPA1-expressing nociceptors $(17,29)$ and induces the release of pro-inflammatory/algogen mediators, like cytokines, substance P (SP), and calcitonin gene-related peptide (CGRP) (29). A dramatic increase of PK2 in sensory neurons, concurrent with the development of painful symptoms, was established in neuropathic conditions, such as peripheral nerve injury (19-21) and diabetic neuropathy (18). Moreover, we recently demonstrated the involvement of PK2 as well as therapeutic effect of its receptor antagonist $\mathrm{PC} 1$ in in vivo murine models of CIPN induced by BTZ (30) and VCR (31). Besides, a possible role for $\mathrm{PK} 2$ as an insult-inducible endangering mediator for cerebral ischemic injury has been proposed (32). PK2 and its receptors are associated with amyloid beta $(A \beta)$ neurotoxicity and mRNA and protein levels of PK2 and its receptors were significantly modified by $A \beta$ treatment $(33,34)$, suggesting that upregulation of PK2 could be common to numerous pathological conditions, such as hypoxia, reactive oxygen species, and excitotoxic glutamate (35).

Based on the involvement of PK2 in murine in vivo CIPN models and the possible role of this protein as an insult-inducible endangering mediator, the aim of this study was to investigate whether PK2 may be involved in direct neurotoxicity induced by two different cytostatic drugs: VCR (microtubules formation inhibitor) and BTZ (26s proteasome inhibitor) on sensory neurons. Given the well-established alterations of neuronal cells following chemotherapy exposure (36-45), we decided to use mouse primary sensory neuron cultures and evaluate the effects of PK-Rs antagonism on neurite outgrowth and immune mediator expression induced by VCR and BTZ.

\section{MATERIALS AND METHODS}

\section{Animals}

Male 9-week-old C57BL/6J mice (Charles River Laboratories, Calco, Italy; Janvier Labs, France) were used in the experiments. Animals were housed in groups of three in translucent polyethylene cages. They were housed with light/dark cycles of $12 \mathrm{~h}$, temperature of $22 \pm 2^{\circ} \mathrm{C}$, humidity of $55 \pm 10 \%$, and standard rodent chow and tap water ad libitum. Animals were acclimatized to the environment for 7 days before starting the experiments. All the procedures performed on animals were in compliance with international policies (EEC council directive 86/609, OJ L 358, 1 Dec. 12, 1987; Guide for the Care and Use of Laboratory Animals, Us National Research Council, 8th ed., 2011) and were approved by the Animal Care and Use Committee of the Italian Ministry of Health (permission number 709/2016) and by the Austrian National Animal Experiment Ethics Committee of the Austrian Bundesministerium für Wissenschaft und Forschung (permit number BMWF-66.011/0054-WF/V/3b/2015). All efforts were made to reduce the number of animals used and to minimize animal suffering in accordance with the 3R principles.

\section{Chemicals}

VCR (Tocris Bioscience, Minneapolis USA) and BTZ (LC Laboratories, Woburn, USA) were freshly prepared before each experiment by dissolving them in sterile PBS solution. These stock solutions were then diluted in culture medium and added to the cell cultures $24 \mathrm{~h}$ after plating DRG primary sensory neurons. Control cells were incubated with vehicle (PBS sterile solution and culture medium). Different concentrations of $\operatorname{VCR}(0.01,0.1,1,5,10,50$, and $100 \mathrm{nM}$ and $1,5,10$, 20, 50, and $100 \mu \mathrm{M})$ and of $\operatorname{BTZ}(4,6,8$, and $10 \mathrm{nM})$ were tested $(39,40)$. The PK-Rs antagonist PC1, a triazineguanidine compound, was provided by G. Balboni, Università di Cagliari, Cagliari, Italy (46). PC1 is a triazine-guanidine derivative that in vitro blocks PK2-induced intracellular $\mathrm{Ca}^{++}$ increase in PK-R1- and PK-R2-transfected CHO cells and in vivo antagonizes hyperalgesia induced by $\mathrm{PK} 2$. Affinity studies for PK-Rs indicated a Ki of 22 and 1,610 nM for PK-R1 and PK-R2, respectively (30). The antagonist was dissolved in sterile deionized water, diluted in culture medium, and added to cell cultures. Different concentrations of PC1 (50, 100, 250, and $500 \mathrm{nM}$ and $1 \mu \mathrm{M})$ were tested $(34,47)$. Control cells were incubated with vehicle containing sterile deionized water and culture medium only. 


\section{DRG Cell Cultures}

Lumbar (L1-L6) DRG were collected from healthy mice (48) and processed as previously described $(49,50)$. Briefly, ganglia were cleaned from connective tissue and incubated in Liberase Blendzyme 1 ( $9 \mathrm{mg} / 100 \mathrm{ml}$ DMEM, Roche) for $1 \mathrm{~h}$, at $37^{\circ} \mathrm{C}, 5 \%$ $\mathrm{CO}_{2}$. After washing with PBS, Trypsin-EDTA (Invitrogen) was added and samples were incubated at $37^{\circ} \mathrm{C}, 5 \% \mathrm{CO}_{2}$ for $15 \mathrm{~min}$. The serum-free TNB 100 basal medium (Biochrom) containing L-glutamine (Invitrogen), penicillin G sodium, streptomycin sulfate (Invitrogen), and protein-lipid complex (Biochrom) was used for washing and cell culturing. The lipid-protein complex acts as a serum substitute that contains a chemically defined amount of important fatty acids, proteins, and vitamins. Inhibitors of non-neuronal cell division were not included in the medium. After mechanical dissociation using a fire-polished Pasteur pipette, the resulting cell suspension was centrifuged at $500 \mathrm{rpm}$ through a $3.5 \%$ BSA gradient (Sigma-Aldrich) for $10 \mathrm{~min}$. The pellet obtained was washed using TNB medium and centrifuged for $5 \mathrm{~min}$ at $760 \mathrm{rpm}$. The pellet was resuspended in TNB medium + murine NGF ( $25 \mathrm{ng} / \mathrm{ml}$, Alomone Labs). Neurons were plated on 12-mm glass coverslips (for neurite outgrowth assay) or in 24-well plates (mRNA extraction, RTqPCR), previously coated with $0.01 \%$ poly-L-lysine (SigmaAldrich) and 1:20 laminin $1 \mathrm{mg} / \mathrm{ml}$ (Sigma-Aldrich). Neurons were cultured in TNB medium with murine NGF $(25 \mathrm{ng} / \mathrm{ml}$, Alomone Labs) at $37^{\circ} \mathrm{C}$ in $5 \% \mathrm{CO}_{2}$ for $24 \mathrm{~h}$. After $24 \mathrm{~h}$, cell health and the presence of first neurites were assessed using a light microscope and different doses of the chemotherapeutic drugs alone or in combination with PC1, PC1 alone, or the vehicle were added. Every $24 \mathrm{~h}$, cells were controlled using a light microscope. After $96 \mathrm{~h}$ of incubation (i.e., $72 \mathrm{~h}$ of drugs exposure), cells were processed for neurite outgrowth assay or RNA extraction and RTqPCR. A schematic representation of the experimental protocol is presented in Figure 1.

\section{Neurite Length and PK2 Evaluation by Immunofluorescence}

DRG neurons were fixed in $4 \%$ PFA for $10 \mathrm{~min}$ at room temperature and, after washing with PBS, permeabilized using $0.1 \%$ Triton-X-100 (3 min incubation). After further washing, blocking buffer (1\% BSA in PBS) was added for $30 \mathrm{~min}$. For total neurite length assessment, cells were incubated with neuronspecific $\beta$-III tubulin (TuiJ-1) monoclonal mouse antibody (1:1,000, R\&D Systems) for $1 \mathrm{~h}$ at room temperature. A chicken secondary antibody anti-mouse IgG Alexa Fluor ${ }^{\mathrm{TM}} 594$ (1:1,000, Thermo Fisher Scientific) was used. Nuclei were counterstained with DAPI ( $1 \mu \mathrm{g} / \mathrm{ml}$, Tocris Bioscience), and finally coverslips were mounted using Mowiol 40-88 (Sigma-Aldrich). Digitalized images of randomly chosen areas of the coverslip were recorded using an Axio Imager microscope (Carl Zeiss) with $20 \times$ objective and a CCD camera (SPOT; Diagnostic Instruments). Only neurons that were clearly separated from neighboring cells were included in the analysis; neurons with no visible process or with only filopodial formations were counted as negative $(49,50)$. Quantification was performed using ImageJ software and NeuronJ plugin [http://www.imagescience.org/meijering/ software/neuronj/;(51)]. The neurite length from at least 80 single neurons for each in vitro treatment condition was measured. Four independent experiments were performed. Total neurite length was calculated for each cell, and then neurite length of the cells belonging to the same experimental conditions were averaged and these values are expressed as mean \pm SEM of all the cells evaluated with $n \geq 80$. This procedure has been used in several other published papers from ours and other groups (49, 50). For PK2 localization, cells were in addition colabeled with a primary rabbit polyclonal antibody for PK2 (1:400, Abcam) overnight at $4^{\circ} \mathrm{C}$. A donkey anti-rabbit IgG Alexa Fluor ${ }^{\mathrm{TM}} 488$ secondary antibody (1:400, Thermo Fisher Scientific) was used. Labeling control (sample section incubated in all of the buffers and detergents used in the experiment, but not in secondary antibody) were performed before starting the experiments. The secondary antibody control (primary antibody replaced with the same amount of $1 \%$ BSA) was included in each experiment.

\section{RNA Extraction and Quantification}

For end point analysis of mRNA expression, total RNA was isolated from cell cultures using TRIzol ${ }^{\circledR}$ reagent (Invitrogen, Thermo Fisher Scientific, Italy) according to the manufacturer's instructions and re-suspended in $20 \mu \mathrm{l}$ of RNase-free water. RNA samples underwent DNAse treatment (DNA-free ${ }^{\mathrm{TM}}$ DNase kit Treatment and Removal Reagents, Ambion, Applied Biosystem, Italy) to avoid false-positive results due to contaminating DNA genomic amplification. RNA quantity and quality were determined using a BioPhotometer (Eppendorf, Germany). From each sample, an equal amount of RNA (1,000 ng) underwent reverse transcription using iScript ${ }^{\mathrm{TM}}$ Reverse Transcription Supermix for RT-qPCR (Bio-Rad, Italy), and the cDNA was used as template for the reverse transcription quantitative polymerase chain reaction (RT-qPCR). Genes of interest were analyzed by RT-qPCR using the following TaqMan Gene Expression Assays (Thermo Fisher Scientific, Waltham, USA): PK2 (Prok2, Mm01182450_g1), PK-R1 (Prokr1, Mm00517546_m1), PKR2 (Prokr2, Mm00769571_m1), IL-1 $\beta$ (Mm00434228_m1), IL-6 (Mm00446190_m1),TNF- $\alpha$ (Mm00443258_m1), IL10 (Mm00439616:m1), TLR4 (Mm00445274_m1), GFAP (Mm01253033_m1), ATF3 (Mm00476033_m1), and GAPDH (Mm99999915_g1). Amplification was performed using ABI PRISM 7000 Sequence Detection System (Applied Biosystem, Foster City, CA) and carried out in a final volume of $20 \mu \mathrm{l}$ consisting of $2 \mu \mathrm{l}$ of cDNA (corresponding to $100 \mathrm{ng}$ of cDNA), $10 \mu \mathrm{l}$ of Luna ${ }^{\circledR}$ Universal Probe qPCR Master Mix (New England BioLabs, Ipswich, MA), $1 \mu$ l of TaqMan Gene Expression Assays (Thermo Fisher Scientific), and RNAse-free water. Experimental procedures were performed according to the TaqMan Gene Expression Assays protocol. Each sample was run in triplicate alongside non-template controls. The PCR cycle protocol used was as follows: $1 \mathrm{~min}$ at $95^{\circ} \mathrm{C}, 40$ five-step cycles of $15 \mathrm{~s}$ at $95^{\circ} \mathrm{C}$, and $30 \mathrm{~s}$ at $60^{\circ} \mathrm{C}$. Threshold cycle numbers (Ct of the specific gene of interest and the endogenous control gene GAPDH) were determined by ABI PRISM 7000 Sequence Detection System (Applied Biosystems ${ }^{\circledR}$, Foster City, USA). The Ct value of the specific gene of interest was normalized to the $\mathrm{Ct}$ value of the endogenous control, GAPDH, and the comparative Ct method 


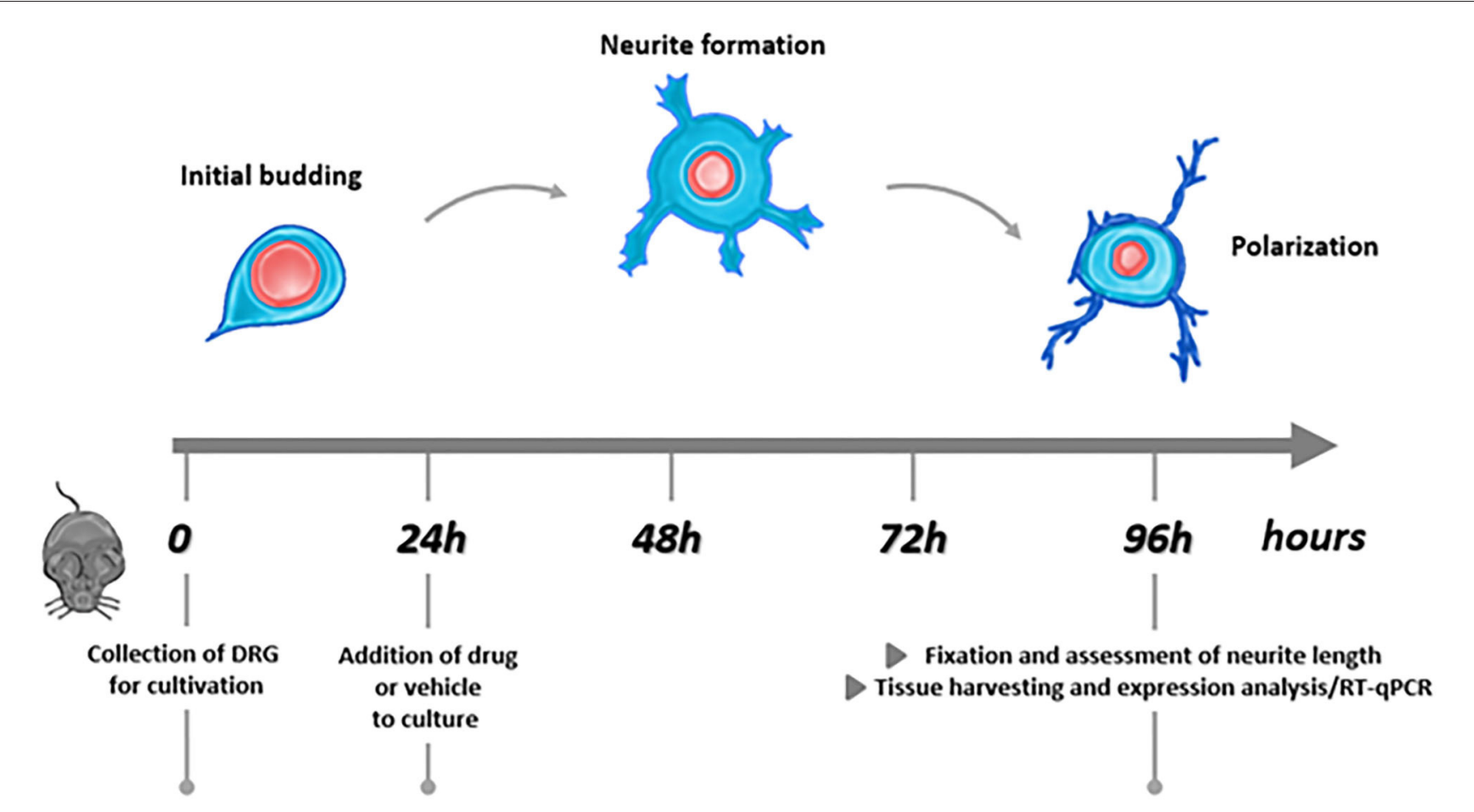

FIGURE 1 | Experimental protocol.

$\left(2^{-\Delta \Delta \mathrm{Ct}}\right)$ was then applied using the specific control group (vehicle treated cells) as a calibrator.

\section{Data Analysis}

Statistical analysis was performed using GraphPad Prism 6 Software (San Diego, CA, USA). Data are presented as mean \pm SEM. For the neurite outgrowth assay, at least 80 cells $(n \geq$ 80 ), obtained from four independent experiments, were scored per experimental condition. Total neurite length was calculated for each cell, and then the neurite lengths of the cells belonging to the same experimental conditions were averaged, and these values are expressed as mean \pm SEM of all the cells evaluated. For the RT-qPCR, eight cultures obtained from eight mice were used. Results were analyzed by using one-way analysis of variance (ANOVA), followed by Bonferroni's post hoc test for multiple comparison. The overall significance level was $p<0.05$ for each hypothesis.

\section{RESULTS}

\section{Dose-Dependent Inhibition of Neurite Length in VCR Treated Neurons}

The cytostatic drug VCR has been associated with clinical neuropathy and loss of epidermal innervation $(12,52)$. As a model for the sensitive peripheral nerve terminal, we used primary cultures of neurons obtained from adult murine DRG. Total neurite length was measured in cell cultures exposed to relevant doses of VCR. Figure 2 shows the quantification of total neurite length with representative examples of cells exposed to rising concentrations (from $0.01 \mathrm{nM}$ to $100 \mu \mathrm{M}$ ) of VCR. As shown, VCR had toxic effects on neurons in a concentrationdependent manner; cells exposed to the lower tested doses 0.01 and $0.1 \mathrm{nM}$ already showed a significant decrease in the total neurite length compared to controls $\left[F_{(13,1,272)}=145.4, p<\right.$ 0.001 ; CTR vs. VCR $0.01 \mathrm{nM}$ and vs. VCR $0.1 \mathrm{nM}, p<0.001$ ]. With higher VCR concentrations, a further reduction of neuronal processes developed and neurites were virtually absent at VCR $50 \mathrm{nM}$ or higher.

\section{Activation of the PK System in Neuron Cultures by VCR}

Given the results obtained in the neurite length assay with VCR and considering our previous study on the contribution of PK2 in VCR-induced neuropathy in vivo (31), we investigated the role of PK2 and its receptors in the neuronal alterations induced by VCR. As shown in Figure 3, neurons and non-neuronal cells expressed PK2 in culture (panel A). Cultures exposed to VCR $1 \mathrm{nM}$ (panel B) displayed significant upregulation of PK2 $\left[F_{3,28}=27.92, p<0.001\right.$;CTR vs. VCR, $\left.p<0.001\right]$ and PK$\mathrm{R} 1\left[F_{3,28}=22.94, p<0.001\right.$; CTR vs. VCR, $\left.p<0.001\right] \mathrm{mRNA}$ expression, while no differences were detected in PK-R2. When cells were simultaneously incubated with the PK-R inhibitor (PC1 $250 \mathrm{nM}$; VCR $1 \mathrm{nM}$ ), both PK2 and PK-R1 upregulation was not present anymore (PK2: VCR vs. VCR + PC1, $p<0.001$; PK-R1: VCR vs. VCR + PC1, $p<0.001)$. PC1 alone at the dose of $250 \mathrm{nM}$ did not induce any changes in the expression levels 


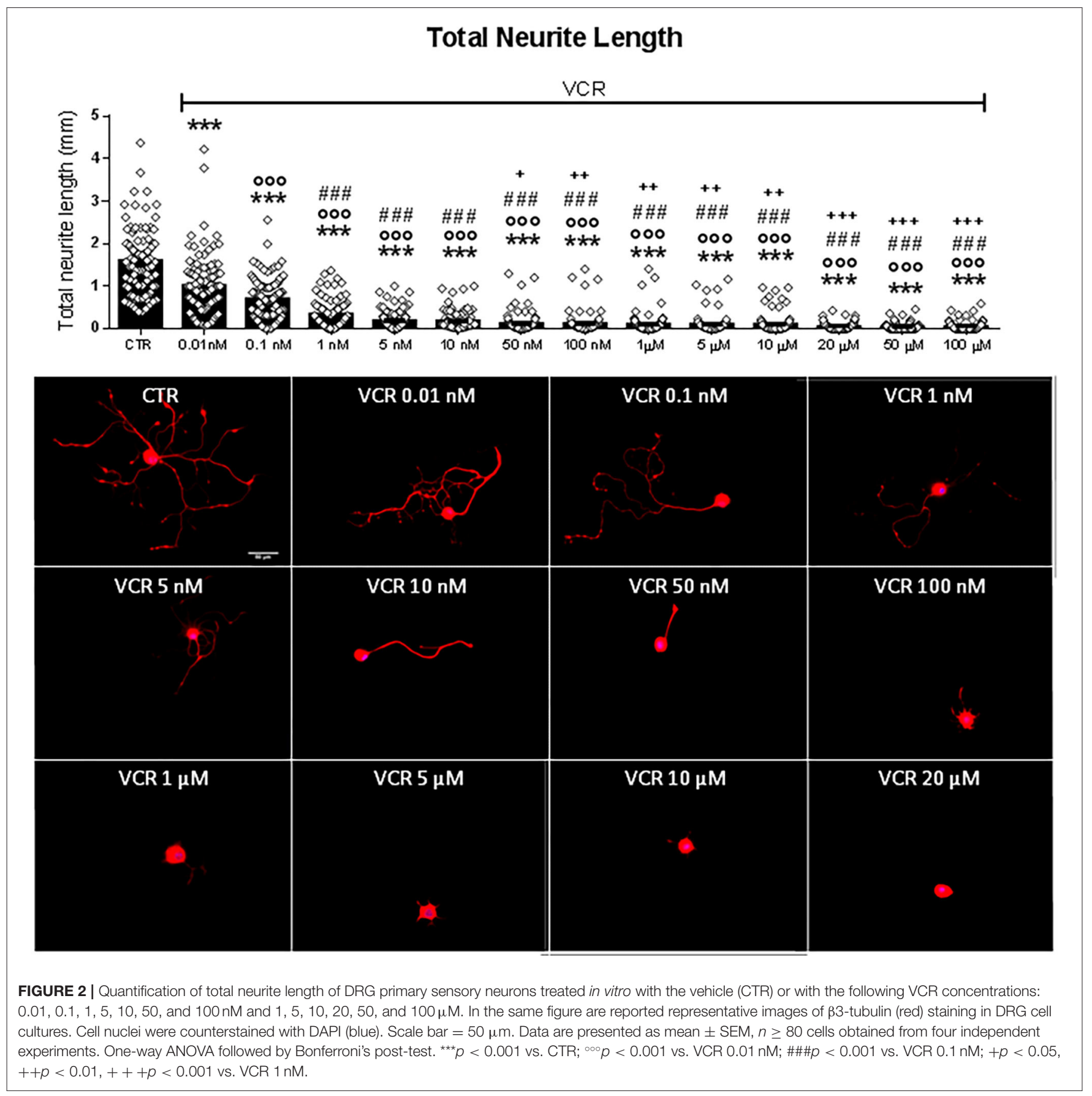

of the PK system components (Figure 3B). This suggests critical involvement of PK2 and PK-R1 in the molecular mechanism of VCR neurotoxicity with an autocrine loop.

\section{Increased Expression of Neuroimmune Markers by VCR}

In addition to PK2 and PK-R1, in the same cultures, VCR $1 \mathrm{nM}$ induced upregulation of several inflammatory and damage markers such as TLR $4\left[F_{3,28}=6.355, p=0.002\right.$; CTR vs. VCR, $p=0.0027], \mathrm{IL}-1 \beta\left[F_{3,28}=4.374, p=0.012\right.$; CTR vs. VCR, $p=$ $0.0153]$, IL-6 [ $F_{3,28}=7.195, p<0.001$; CTR vs. VCR $\left.p=0.0051\right]$, IL-10 $\left[F_{3,28}=4.383, p=0.012\right.$; CTR vs. VCR, $\left.p=0.0369\right]$, and ATF3 $\left[F_{3,28}=60.800, p<0.001\right.$; CTR vs. VCR, $\left.p<0.001\right]$. In this experimental condition (VCR $1 \mathrm{nM}$ ), no alterations in the expression of TNF- $\alpha$ or GFAP were observed (Figure 4). The changes induced by VCR $(1 \mathrm{nM})$ were significantly reduced when cells were simultaneously incubated with $250 \mathrm{nM}$ PC1 (VCR vs. VCR + PC1: TLR4, $p=0.010$; IL-6, $p=0.011$; IL-10, $p=0.019$; ATF3, $p<0.001)$. These findings indicate that the PK system not 
A


B

PK2



PK-R1

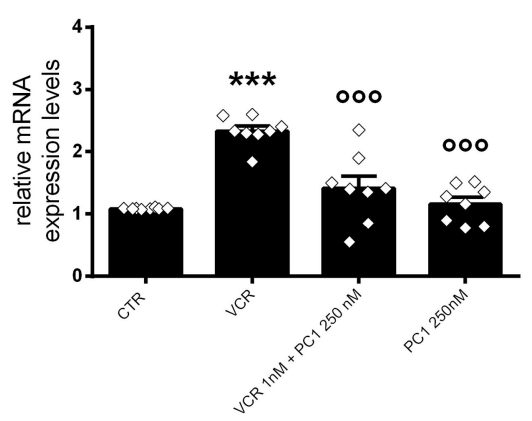

PK-R2

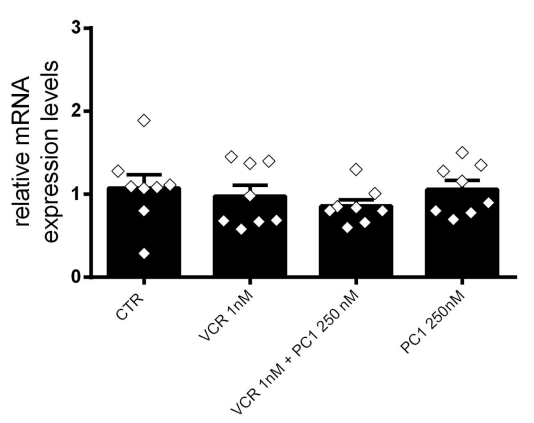

FIGURE 3 | (A) Shows representative images of $\beta 3$-tubulin (Tuj1; red), PK2 (green), and DAPI (blue) signal in vehicle-treated DRG cell cultures. Scale bar = $10 \mu \mathrm{m}$. (B) represents the expression levels of PK2, PK-R1, and PK-R2 that were measured in DRG cultures treated with vehicle (CTR), VCR 1 nM alone, or in combination with PC1 250 nM (VCR + PC1) and PC1 250 nM without the chemotherapeutic agent. mRNA levels, determined by RT-qPCR, were expressed in relation to GAPDH and presented as fold increases over the levels of CTR condition (relative mRNA expression levels). Data are presented as mean \pm SEM of eight cultures obtained from eight animals. Statistical analysis was performed by means of one-way ANOVA followed by Bonferroni's post-test. ${ }^{\star \star \star} p<0.001$ vs. CTR; ${ }^{\circ 00} p<0.001$ vs. VCR 1 nM.

only is involved in the autocrine regulation of PK2 and PK-R1 but also has a critical role in a downstream neuroinflammatory component of VCR neurotoxicity.

\section{Prevention of VCR-Induced Neurite Outgrowth Inhibition by PK-R Antagonist PC1}

Based on these findings, we tested PC1 together with VCR concentrations that induced a reduction of neurite outgrowth when compared not only to vehicle-treated cells but also one vs. the other $(0.01,0.1,1$, and $50 \mathrm{nM})$. PC1 was effective in reducing the neurite alterations induced by VCR $0.01,0.1$, and $1 \mathrm{nM}\left[F_{(8,723)}=76.89, p<0.001\right.$; VCR 0.01, 0.1, and $1 \mathrm{nM}$ vs. VCR $+\mathrm{PC} 1, p<0.001$ ], while no positive effect of PC1 $250 \mathrm{nM}$ was observed in neurons exposed to $50 \mathrm{nM}$ VCR (Figure 5). This suggests that PK2 activation of PK-R1, as a consequence of VCR application, is a major component of the molecular mechanism involved in VCR neurotoxicity affecting sensory neurons.

\section{PC1 Prevents Neurotoxic BTZ Effects on Sensory Neuron Fibers}

In order to validate the neuroprotective effects of PC1, we used BTZ as an antineoplastic drug with different mechanism of action but also able to induce CIPN. We assessed the neurite outgrowth in DRG primary sensory neuron cultures treated with four different nanomolar doses $(4,6,8$, and $10 \mathrm{nM})$ of BTZ (Figure 6). Cells exposed for $72 \mathrm{~h}$ to the lowest BTZ concentration $(4 \mathrm{nM})$ did not show any decline in total neurite length in comparison to CTR. However, by increasing the concentration of the chemotherapeutic drug (BTZ $6 \mathrm{nM})$, a significant decrease of total neurite length was detected $\left[F_{(4,437)}\right.$ 


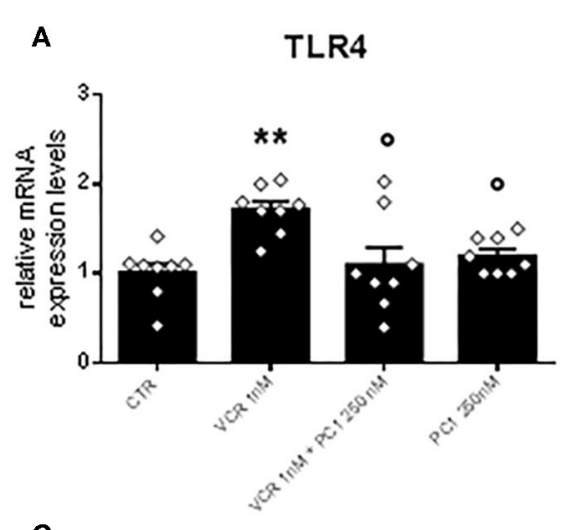

c

IL-6

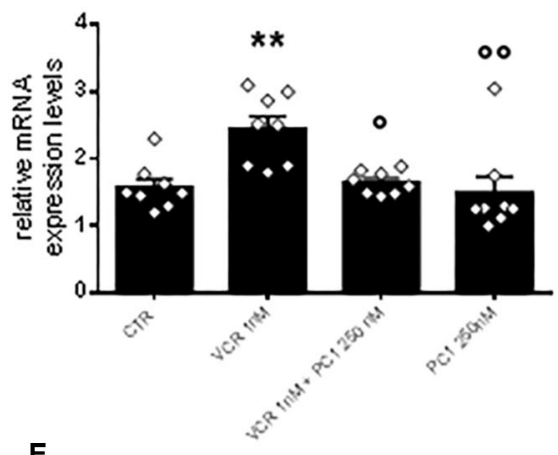

IL-10

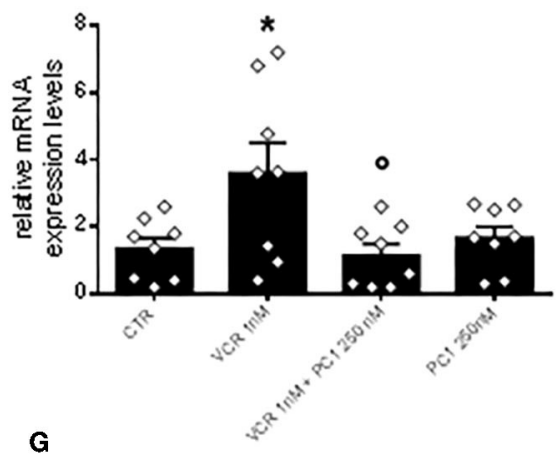

ATF3



B

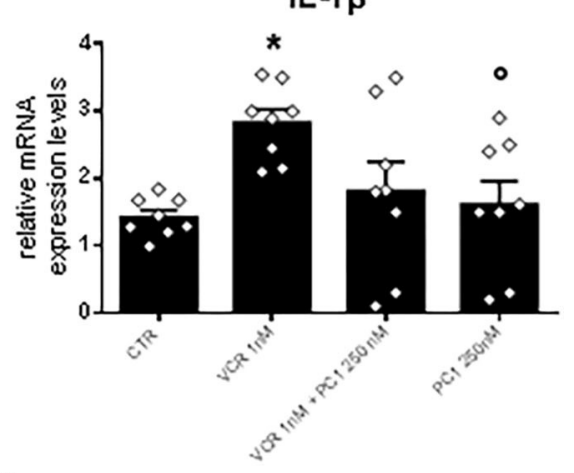

D

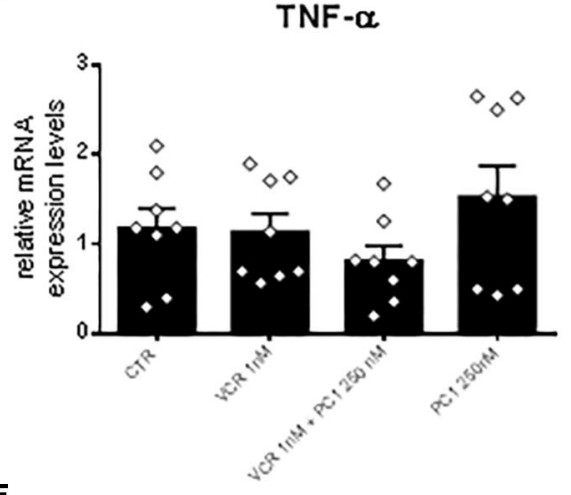

$\mathbf{F}$

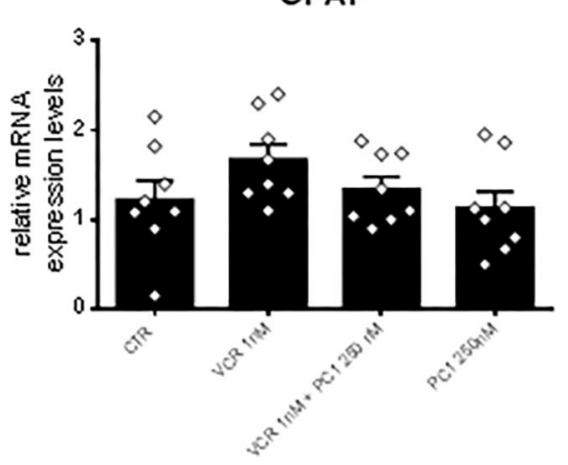

FIGURE 4 | Expression levels of TLR4 (A), IL-1 $\beta$ (B), IL-6 (C), TNF- $\alpha$ (D), IL-10 (E), GFAP (F), and ATF3 (G), measured in DRG cell cultures treated with vehicle, VCR $1 \mathrm{nM}$ alone, or in association with PC1 250 and PC1 $250 \mathrm{nM}$ without the chemotherapeutic agent. mRNA levels, determined by RT-qPCR, were expressed in relation to GAPDH and presented as fold increases over the levels of CTR condition (relative mRNA expression levels). Data are the mean \pm SEM of eight cultures obtained 
FIGURE 4 | from eight mice. Statistical analysis was performed by means of one-way ANOVA followed by Bonferroni's post-test. ${ }^{\star} p<0.05,{ }^{\star \star} p<0.01,{ }^{\star \star \star} p<0.001$ vs. CTR; ${ }^{\circ} p<0.05,{ }^{\circ} p<0.01,{ }^{\circ 0} p<0.001$ vs. VCR $1 \mathrm{nM}$.

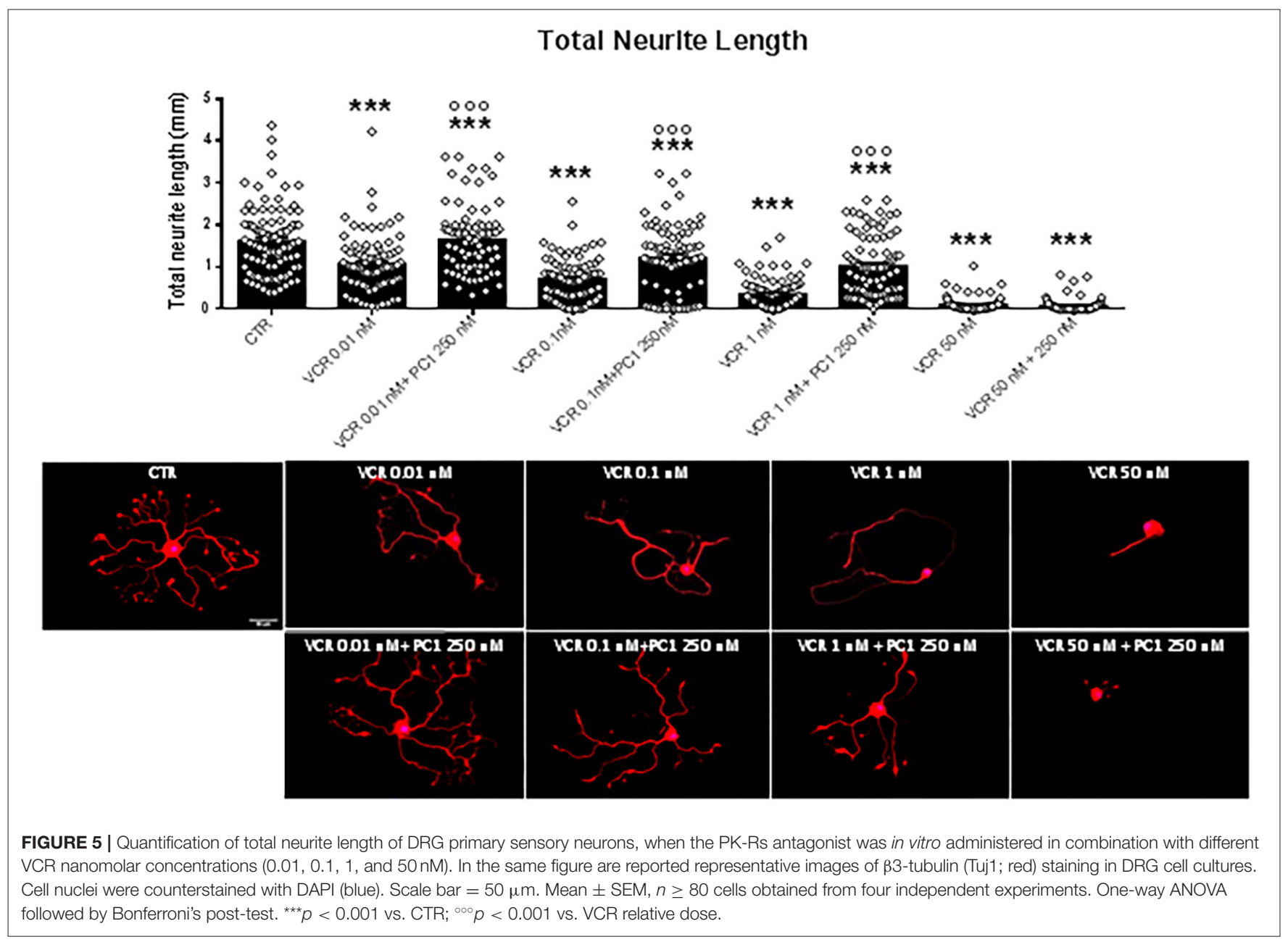

$=114.80, p<0.001$; CTR vs. BTZ $6 \mathrm{nM}, p<0.001]$, and with higher BTZ concentrations ( 8 and $10 \mathrm{nM}$ ), the neurotoxic effect on neurite length was further aggravated (CTR vs. BTZ 8 and $10 \mathrm{nM}, p<0.001$; BTZ $6 \mathrm{nM}$ vs. BTZ $8 \mathrm{nM}$ and $10 \mathrm{nM}$ $p<0.001$ ). Since BTZ $6 \mathrm{nM}$ induced about $50 \%$ reduction in neurite length, this concentration was used to investigate the protective effects of PC1. Rising concentrations of PC1 (50, $100,250,500 \mathrm{nM}$, and $1 \mu \mathrm{M}$ ) were tested alone (Figure 7A) or co-applied with BTZ $6 \mathrm{nM}$ for $72 \mathrm{~h}$ (Figure 7B). PC1 alone did not modify neurite outgrowth up to $500 \mathrm{nM}$, and only at the highest dose did PC1 itself slightly reduce neurite length (panel A). However, PC1 significantly counteracted the BTZinduced reduction of total neurite length (panel B). At lower PC1 doses (50 and $100 \mathrm{nM}$ ), a slight but significant increase of total neurite length compared to BTZ-only treated cells was already evident $\left[F_{(6,623)}=23.04, p<0.001\right.$; BTZ vs. BTZ + PC1 $50 \mathrm{nM}, p=0.0048$ and vs. BTZ + PC1 $100 \mathrm{nM}, p$ $=0.0089$. Increasing the concentration of the antagonist to
$250 \mathrm{nM}$, a stronger improvement was observed (BTZ vs. BTZ + PC1 $250 \mathrm{nM}, p=0.0002)$.

\section{DISCUSSION}

In the present study, we found that the PK-R antagonist PC1 was able to prevent the neurotoxic effect exerted on primary sensory neurons by two different chemotherapeutic drugs, VCR and BTZ in vitro. An upregulation of PK2 and PK-R1 but not PK-R2 receptors was present in VCR-treated cultures, and the $\mathrm{PK}-\mathrm{R}$ antagonism significantly reduced this upregulation of PK2 and PK-R1 receptor along with an additional effect on upregulated neuroimmune mediators. PK2 localizes in both neurons and non-neuronal cells, possibly satellite cells, present in the culture. This is in accordance with literature showing the presence of PK2 and its receptors (PK-R1 and PK-R2) in both neurons and surrounding accessory cells $(25,34,47,53)$. In addition, a functional association between PK2, TRPV1, and 


\section{Total Neurite Length}
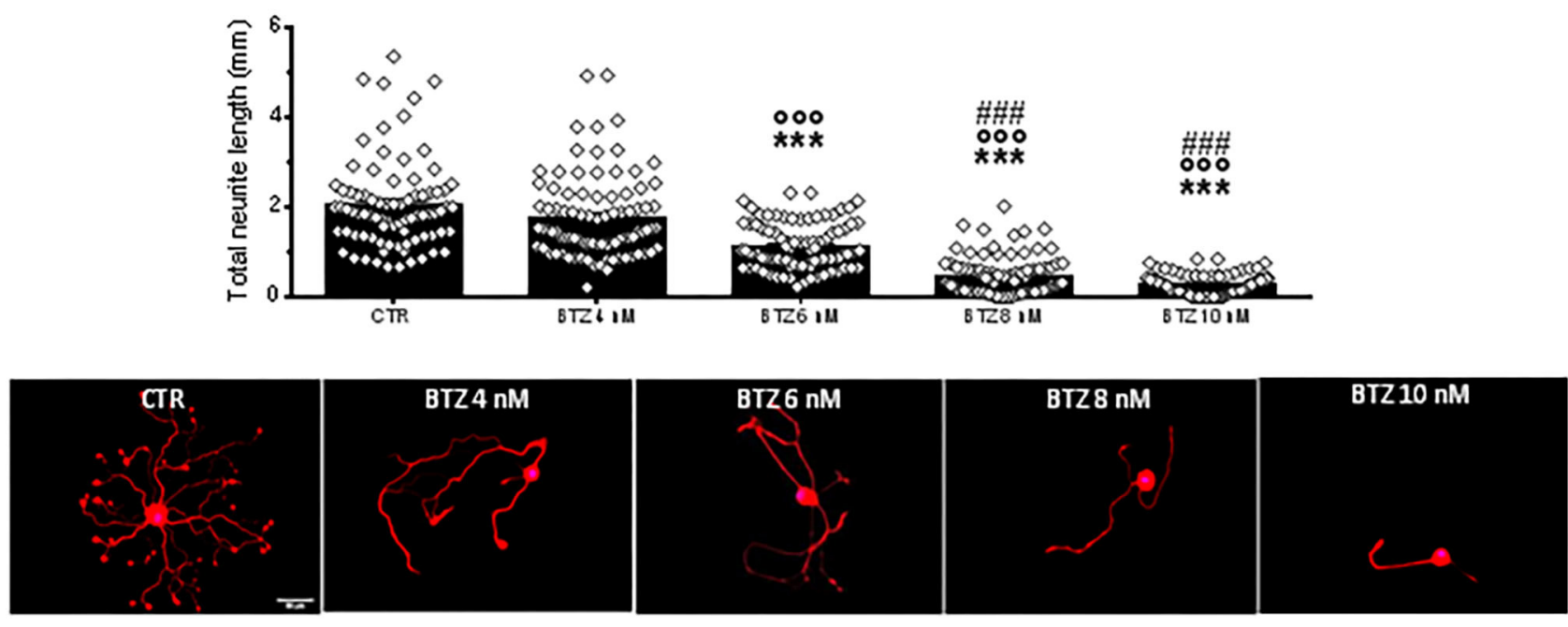

FIGURE 6 | Quantification of total neurite length of DRG primary sensory neurons exposed in vitro to the vehicle (CTR) and 4 nanomolar doses of BTZ. In the same figure are reported representative pictures of $\beta 3$-tubulin (Tuj1; red) staining in DRG cell cultures treated in vitro with the vehicle (CTR) or with the following BTZ concentrations: 4, 6, 8, and $10 \mathrm{nM}$. Cell nuclei were counterstained with DAPI (blue). Scale bar $=50 \mu \mathrm{m}$. Data are presented as mean \pm SEM, $n \geq 80$ cells obtained from four independent experiments. One-way ANOVA followed by Bonferroni's post-test. ${ }^{* \star} p<0.001$ vs. CTR; ${ }^{\circ 00} p<0.001$ vs. BTZ 4 nM; $p<0.001$ vs. BTZ 6 nM.

TRPA1 in DRG neurons has been reported $(29,53,54)$. PK2 and PK-Rs in DRG have been found to be expressed mostly, although not uniquely, in small peptidergic neurons (29). From our immunofluorescence study, PK2 positive staining appears to be present in all cultured neurons, although further experiments better assessing localization of PK2 in different types of neurons, such as peptidergic or not peptidergic neurons, would be of interest. Our findings are in line with our recent in vivo studies on CIPN induced by BTZ (30) and VCR (31) in mice, demonstrating not only that the PK system is involved in the maintenance of CIPN induced by these two drugs but also that inhibition of PK-Rs ameliorates the signatures of pain behavior and reduces the neuroimmune activation at the level of the peripheral and central nervous system. PK2 can be upregulated by different pathological factors, such as hypoxia, reactive oxygen species, and excitotoxic glutamate, leading to the hypothesis that PK2 could have a general role as an insult-inducible endangering mediator for neuronal damages (32-35). It is now well accepted that the free nerve endings of primary sensory afferents, but also satellite cells, are susceptible to anticancer agents, such as BTZ and VCR, because of the lack of the blood-brain barrier and the presence of fenestrated capillaries, which lead to an unrestrained drug permeation $(3,13-15)$. For this reason, in addition to in vivo animal models (55), numerous in vitro studies have been carried out, mainly on sensory neuron cultures, in order to investigate the molecular mechanisms at the basis of chemotherapy-induced neurotoxicity $(36,52)$. Here, we used the adult DRG neuron in vitro model and the quantification of total neurite length as morphological read-out that correlates with neuron function and health (56). In general, a small percentage of non-neuronal cells, such as satellite cells and macrophages are contaminating in this type of culture (3840). In order to obtain pure neuronal cultures, the use of an anti-mitotic agent is needed, but this is considered a toxic treatment that can interfere with neuronal viability (40, 57$60,71)$. Furthermore, the presence of satellite cells in DRG cultures is useful because it resembles more closely the in vivo environment of sensory neurons $(36,39,61)$. Cytostatic drugs turn down tumor growth via different molecular mechanisms targeting tumor cell division and survival. Despite the different mechanisms of action, the majority of these drugs are neurotoxic. Both VCR and BTZ induce neurotoxic damage, as demonstrated by the increased levels of cell stress as indicated by upregulation of the damage marker ATF3 found by us and others (5, 30, $31,62)$. Chemotherapeutic agents can directly bind to toll like receptor 4 (TLR4) $(13,63)$, which triggers the activation of several pro-inflammatory pathways. The upregulation of proinflammatory cytokines, such as IL- 6 and IL-1 $\beta$, subsequently induces the activation of STAT3 that binds to the PK2 promoter and induces the activation and further production of PK2 (64). Since reactive oxygen species (ROS) can induce PK2 expression (32) and VCR has been constantly shown to activate ROS in neurons (4), we can also hypothesize that VCR-induced ROS may contribute to PK2 overexpression. The present study for the first time presents evidence that this pathway can be relevant for the damage induced in sensory neurons since increased levels of PK2 were identified in VCR-treated neuron cultures and the increase was abolished by PC1. Once activated, PK2 is able to sustain its own production in a positive loop and to amplify the pro-inflammatory signal as demonstrated by several in vivo and in vitro studies $(22,26,65,66)$. In line with these reports, PC1 reduced not only expression of PK2 and PK-R1 
A

Total Neurite Length

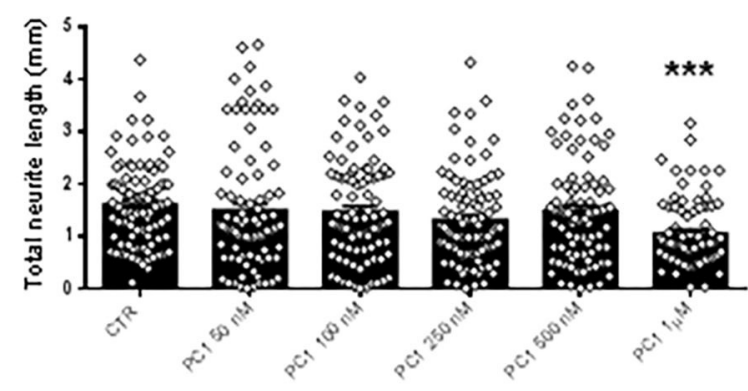

B
Total Neurite Length

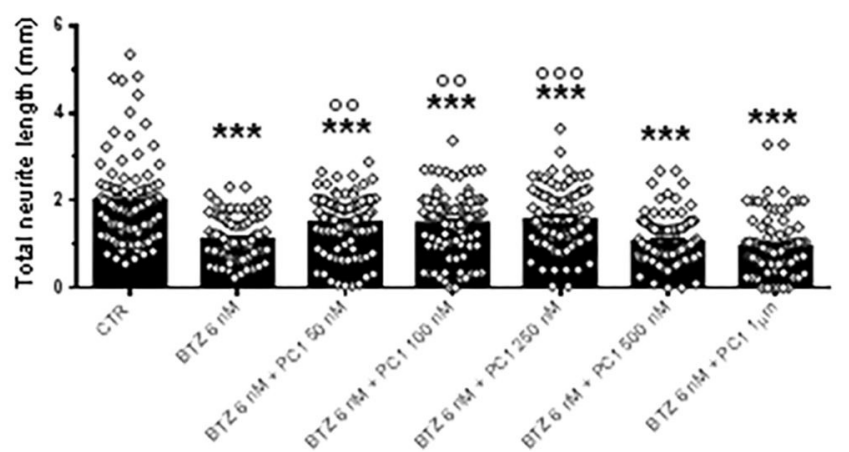


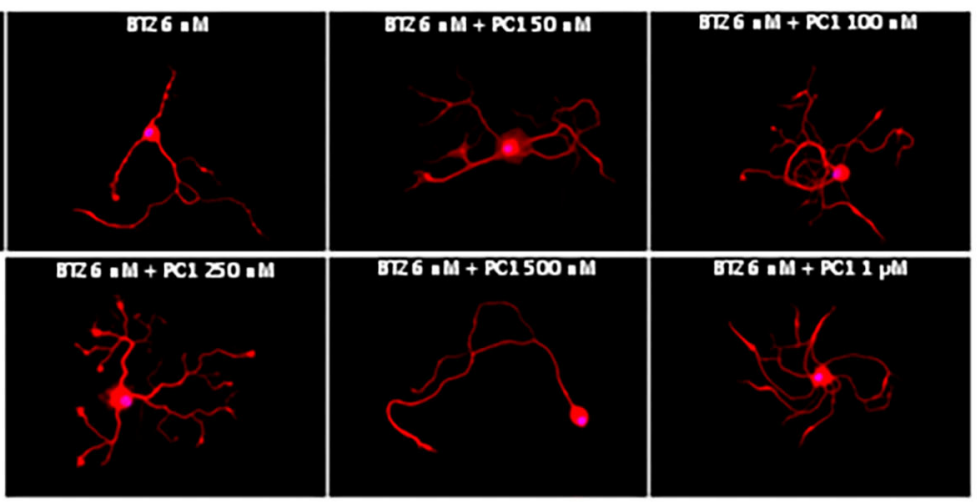

FIGURE 7 | Quantification of total neurite length of CTR cells and the effect of different doses ( $50 \mathrm{nM}, 100 \mathrm{nM}, 250 \mathrm{nM}, 500 \mathrm{nM}$, and $1 \mu \mathrm{M}$ ) of the PK-Rs antagonist PC1 on DRG primary sensory neurons outgrowth, in vitro administered alone (A) or in combination with BTZ $6 \mathrm{nM}$ (B). In the same figure are reported representative images of $\beta 3$-tubulin (Tuj1; red) staining in DRG cell cultures exposed to the vehicle (CTR), BTZ $6 \mathrm{nM}$, and BTZ $6 \mathrm{nM}$ in combination with PC1 $50 \mathrm{nM}$, PC1 $100 \mathrm{nM}$, PC1 $250 \mathrm{nM}$, PC1 $500 \mathrm{nM}$, and PC1 $1 \mu \mathrm{M}$. Cell nuclei were counterstained with DAPI (blue). Scale bar $=50 \mu \mathrm{m}$. Data are presented as mean \pm SEM, $n \geq 80$ cells obtained from four independent experiments. One-way ANOVA followed by Bonferroni's post-test. ${ }^{\star \star \star} p<0.001$ vs. CTR; ${ }^{\circ 0} p<0.01,{ }^{\circ 00} p<0.001$ vs. BTZ 6 nM.

but also that of several pro-inflammatory cytokines, suggesting that PK2 via PK-R1 may act as upstream regulator of cytokine expression. Based on our results, we propose that the PK-R antagonist PC1, by selectively binding to PK2 receptors, reduces or even prevents the propagation of a "damage signal" induced by chemotherapeutics. Apparently, in the presence of PC1, the cell stress and injury response characterized by an upregulation of pro-inflammatory cytokines and ATF3 was profoundly reduced. The specificity of the antagonist and the lack of off-target effects are supported by several published evidences. In vivo, when administered alone in normal mice, PC1 did not induce behavioral/biochemical alterations $(18,22)$. The antagonist did not counteract hypersensitivity induced by PGE2, ATP, or bradykinin. Other PK-Rs peptidic or non-peptidic antagonsists exert anti-inflammatory and modulatory effects similar to those induced by PC1 in vivo and in vitro $(21,47,67,68)$. All these results seem to indicate that $\mathrm{PC} 1$ is effective in blocking $\mathrm{PK} 2$ activity when endogenously overexpressed.

We are aware that a limitation of this study could be that the PK system, markers, and cytokines are evaluated only as
mRNA levels. However, in our previous works that evaluated PK system and pro-inflammatory mediators in DRG in ex vivo experiments, mRNA and protein were similarly modulated $(18,21,30)$. Moreover, other authors, using primary cortical neurons, demonstrated a parallel modulation of the PK system as mRNA and protein $(34,47)$. Despite their different antineoplastic mechanisms of action, both chemotherapeutic agents used in our study induced a dose-dependent decline of neurite length. However, VCR had a prominently stronger neurotoxic effect than BTZ. This is in accordance with clinical data in which VCR appears to be more toxic and induces CIPN in a larger number of patients at lower doses compared to BTZ $(69,70)$.

Interestingly, our results confirm the high vulnerability of DRG to the neurotoxic effect of chemotherapeutics and suggest that DRG-resident cells, both neuronal and non-neuronal, are sufficient to trigger and sustain a neuroinflammatory condition. In addition, also the protective effect on axonopathy obtained by PK blocking is exerted without the involvement or recruiting of infiltrating peripheral immune cells. 
In conclusion, our findings suggest that the PK system contributes to the neurotoxic effect started in sensory neurons by anti-neoplastic agents underlying chemotherapy-induced neuropathic pain and sensory deficits. Blocking PK2 signaling by $\mathrm{PC} 1$ emerges as a promising therapeutic approach as this molecule not only reduces signatures of CIPN in vivo $(30,31)$ but also, by protecting neurons, could prevent and suppress the causes underlying progression of neuropathic pain during chemotherapeutic treatment.

\section{DATA AVAILABILITY STATEMENT}

All datasets generated for this study are included in the article/supplementary material.

\section{ETHICS STATEMENT}

The animal study was reviewed and approved by Animal Care and Use Committee of the Italian Ministry of Health (permission number 709/ 2016) and the Austrian National Animal Experiment Ethics Committee of the Austrian Bundesministerium für Wissenschaft und Forschung (permit number BMWF-66.011/0054-WF/V/3b/2015).

\section{REFERENCES}

1. Colvin LA. Chemotherapy-induced peripheral neuropathy: where are we now? Pain. (2019) 160 (Suppl. 1):S1-10. doi: $10.1097 /$ j.pain.0000000000001540

2. Boyette-Davis JA, Hou S, Abdi S, Dougherty PM. An updated understanding of the mechanisms involved in chemotherapy-induced neuropathy. Pain Manag. (2018) 8:363-75. doi: 10.2217/pmt-2018-0020

3. Flatters S, Dougherty PM, Colvin LA. Clinical and preclinical perspectives on Chemotherapy-Induced Peripheral Neuropathy (CIPN): a narrative review. Br J Anaesth. (2017) 119:737-49. doi: 10.1093/bja/aex229

4. Boyette-Davis JA, Walters ET, Dougherty PM. Mechanisms involved in the development of chemotherapy-induced neuropathy. Pain Manag. (2015) 5:285-96. doi: 10.2217/pmt.15.19

5. Han Y, Smith MT. Pathobiology of cancer chemotherapy-induced peripheral neuropathy (CIPN). Front Pharmacol. (2013) 4:156. doi: $10.3389 /$ fphar.2013.00156

6. Starobova H, Vetter I. Pathophysiology of chemotherapy-induced peripheral neuropathy. Front Mol Neurosci. (2017) 10:174. doi: 10.3389/fnmol.2017.00174

7. Boyette-Davis JA, Cata JP, Driver LC, Novy DM, Bruel BM, Mooring DL, et al. Persistent chemoneuropathy in patients receiving the plant alkaloids paclitaxel and vincristine. Cancer Chemother Pharmacol. (2013) 71:619-26. doi: 10.1007/s00280-012-2 047-z

8. Krishnan AV, Goldstein D, Friedlander M, Kiernan MC. Oxaliplatin-induced neurotoxicity and the development of neuropathy. Muscle Nerve. (2005) 32:51-60. doi: 10.1002/mus.20340

9. Iñiguez C, Larrodé P, Mayordomo JI, González P, Adelantado S, Yubero A, et al. Reversible peripheral neuropathy induced by a single administration of high-dose paclitaxel. Neurology. (1998) 51:868-70. doi: 10.1212/WNL.51. 3.868

10. Gregg RW, Molepo JM, Monpetit VJ, Mikael NZ, Redmond D, Gadia M, et al. Cisplatin neurotoxicity: the relationship between dosage, time, and platinum concentration in neurologic tissues, and morphologic evidence of toxicity. J Clin Oncol. (1992) 10:795-803. doi: 10.1200/JCO.1992.10. 5.795

\section{AUTHOR CONTRIBUTIONS}

GM and TK: methodology, data curation, and formal analysis. GM wrote the original paper. GA: data curation, review, and editing. RL: review. PS and MK: conceptualization, supervision, and writing-review and editing. SF: supervision, funding acquisition, and writing-review and editing. All authors contributed to the article and approved the submitted version.

\section{FUNDING}

This work was supported by Fondazione Cariplo, Italy (grant no. 2015-0897 to SF). GM was supported by the cycle XXXII of the doctorate in Experimental and Clinical Pharmacological Sciences, Università degli Studi di Milano, Milan, Italy.

\section{ACKNOWLEDGMENTS}

The authors thank T. Martha, K. Braun, and M. Doblander (all from Innsbruck Medical University) for expert technical assistance.

11. Lipton RB, Apfel SC, Dutcher JP, Rosenberg R, Kaplan J, Berger A, et al. Taxol produces a predominantly sensory neuropathy. Neurology. (1989) 39:368-73. doi: 10.1212/WNL.39.3.368

12. Siau C, Xiao W, Bennett GJ. Paclitaxel- and vincristine-evoked painful peripheral neuropathies: loss of epidermal innervation and activation of Langerhans cells. Exp Neurol. (2006) 201:507-14. doi: 10.1016/j.expneurol.2006.05.007

13. Montague K, Malcangio M. The therapeutic potential of monocyte/macrophage manipulation in the treatment of chemotherapyinduced painful neuropathy. Front Mol Neurosci. (2017) 10:397. doi: $10.3389 /$ fnmol.2017.00397

14. Lees JG, Makker PG, Tonkin RS, Abdulla M, Park SB, Goldstein D, et al. Immune-mediated processes implicated in chemotherapy-induced peripheral neuropathy. Eur J Cancer. (2017) 73:22-9. doi: 10.1016/j.ejca.2016.12.006

15. Carozzi VA, Canta A, Chiorazzi A. Chemotherapy-induced peripheral neuropathy: what do we know about mechanisms? Neurosci Lett. (2015) 596:90-107. doi: 10.1016/j.neulet.2014.10.014

16. Zhao Y, Wu J, Wang X, Jia H, Chen DN, Li JD. Prokineticins and their G protein-coupled receptors in health and disease. Progr Mol Biol Transl Sci. (2019) 161:149-79. doi: 10.1016/bs.pmbts.2018.09.006

17. Negri L, Lattanzi R, Giannini E, Melchiorri P. Bv8/Prokineticin proteins and their receptors. Life Sci. (2007) 81:1103-16. doi: 10.1016/j.lfs.2007.08.011

18. Castelli M, Amodeo G, Negri L, Lattanzi R, Maftei D, Gotti C, et al. Antagonism of the prokineticin system prevents and reverses allodynia and inflammation in a mouse model of diabetes. PLoS ONE. (2016) 11:e0146259. doi: 10.1371/journal.pone.0146259

19. Guida F, Lattanzi R, Boccella S, Maftei D, Romano R, Marconi V, et al. PC1, a non-peptide PKR1-preferring antagonist, reduces pain behavior and spinal neuronal sensitization in neuropathic mice. Pharmacol Res. (2015) 91:36-46. doi: 10.1016/j.phrs.2014.11.004

20. Lattanzi R, Maftei D, Marconi V, Florenzano F, Franchi S, Borsani E, et al. Prokineticin 2 upregulation in the peripheral nervous system has a major role in triggering and maintaining neuropathic pain in the chronic constriction injury model. BioMed Res Int. (2015) 2015:301292. doi: 10.1155/2015/301292

21. Maftei D, Marconi V, Florenzano F, Giancotti LA, Castelli M, Moretti S, et al. Controlling the activation of the Bv8/prokineticin system reduces neuroinflammation and abolishes thermal and tactile 
hyperalgesia in neuropathic animals. Br J Pharmacol. (2014) 171:4850-65. doi: 10.1111/bph.12793

22. Giannini E, Lattanzi R, Nicotra A, Campese AF, Grazioli P, Screpanti I, et al. The chemokine Bv8/prokineticin 2 is up-regulated in inflammatory granulocytes and modulates inflammatory pain. Proc Natl Acad Sci USA. (2009) 106:14646-51. doi: 10.1073/pnas.0903720106

23. LeCouter J, Lin R, Frantz G, Zhang Z, Hillan K, Ferrara N. Mouse endocrine gland-derived vascular endothelial growth factor: a distinct expression pattern from its human ortholog suggests different roles as a regulator of organ-specific angiogenesis. Endocrinology. (2003) 144:2606-16. doi: 10.1210/en.2002-0146

24. Masuda Y, Takatsu Y, Terao Y, Kumano S, Ishibashi Y, Suenaga M, et al. Isolation and identification of EG-VEGF/prokineticins as cognate ligands for two orphan G-protein-coupled receptors. Biochem Biophys Res Commun. (2002) 293:396-402. doi: 10.1016/S0006-291X(02)00239-5

25. Negri L, Ferrara N. The prokineticins: neuromodulators and mediators of inflammation and myeloid cell-dependent angiogenesis. Physiol Rev. (2018) 98:1055-82. doi: 10.1152/physrev.00012.2017

26. Negri L, Maftei D. Targeting the prokineticin system to control chronic pain and inflammation. Curr Med Chem. (2018) 25:3883-94. doi: $10.2174 / 0929867324666170713102514$

27. Lin DC, Bullock CM, Ehlert FJ, Chen JL, Tian H, Zhou QY. Identification and molecular characterization of two closely related $\mathrm{G}$ protein-coupled receptors activated by prokineticins/endocrine gland vascular endothelial growth factor. J Biol Chem. (2002) 277:19276-80. doi: 10.1074/jbc.M202139200

28. Soga T, Matsumoto SI, Oda T, Saito T, Hiyama H, Takasaki J, et al. (2002). Molecular cloning and characterization of prokineticin receptors. Biochim Biophys Acta. 1579, 173-179. doi: 10.1016/S0167-4781(02)00546-8

29. Vellani V, Colucci M, Lattanzi R, Giannini E, Negri L, Melchiorri $P$, et al. Sensitization of transient receptor potential vanilloid 1 by the prokineticin receptor agonist Bv8. J Neurosci. (2006) 26:5109-16. doi: 10.1523/JNEUROSCI.3870-05.2006

30. Moschetti G, Amodeo G, Maftei D, Lattanzi R, Procacci P, Sartori $\mathrm{P}$, et al. Targeting prokineticin system counteracts hypersensitivity, neuroinflammation, and tissue damage in a mouse model of bortezomibinduced peripheral neuropathy. $J$ Neuroinflamm. (2019) 16:89. doi: 10.1186/s12974-019-1461-0

31. Moschetti G, Amodeo G, Paladini MS, Molteni R, Balboni G, Panerai A, et al. Prokineticin 2 promotes and sustains neuroinflammation in vincristine treated mice: focus on pain and emotional like behavior. Brain Behav Immunity. (2019) 82:422-31. doi: 10.1016/j.bbi.2019.09.012

32. Cheng MY, Lee AG, Culbertson C, Sun G, Talati RK, Manley NC, et al. Prokineticin 2 is an endangering mediator of cerebral ischemic injury. Proc Natl Acad Sci USA. (2012) 109:5475-80. doi: 10.1073/pnas.1113363109

33. Maftei D, Ratano P, Fusco I, Marconi V, Squillace S, Negri L, et al. The prokineticin receptor antagonist PC1 rescues memory impairment induced by $\beta$ amyloid administration through the modulation of prokineticin system. Neuropharmacology. (2019) 158:107739. doi: 10.1016/j.neuropharm.2019.107739

34. Severini C, Lattanzi R, Maftei D, Marconi V, Ciotti MT, Petrocchi Passeri P, et al. Bv8/prokineticin 2 is involved in A $\beta$-induced neurotoxicity. Sci Rep. (2015) 5:15301. doi: 10.1038/srep15301

35. Zuena AR, Casolini P, Lattanzi R, Maftei D. Chemokines in Alzheimer's disease: new insights into prokineticins, chemokine-like proteins. Front Pharmacol. (2019) 10:622. doi: 10.3389/fphar.2019.00622

36. Malacrida A, Meregalli C, Rodriguez-Menendez V, Nicolini G. Chemotherapy-induced peripheral neuropathy and changes in cytoskeleton. Int J Mol Sci. (2019) 20:2287. doi: 10.3390/ijms20092287

37. Livni L, Lees JG, Barkl-Luke ME, Goldstein D, Moalem-Taylor G. Dorsal root ganglion explants derived from chemotherapy-treated mice have reduced neurite outgrowth in culture. Neurosci Lett. (2019) 694:14-9. doi: 10.1016/j.neulet.2018.11.016

38. Leisengang S, Ott D, Murgott J, Gerstberger R, Rummel C, Roth J. Primary cultures from rat dorsal root ganglia: responses of neurons and glial cells to somatosensory or inflammatory stimulation. Neuroscience. (2018) 394:1-13. doi: 10.1016/j.neuroscience.2018.10.018

39. Guo L, Hamre J III, Eldridge S, Behrsing HP, Cutuli FM, Mussio J, Davis M. Editor's highlight: multiparametric image analysis of rat dorsal root ganglion cultures to evaluate peripheral neuropathy-inducing chemotherapeutics. Toxicol Sci. (2017) 156:275-88. doi: 10.1093/toxsci/kfw254

40. Alé A, Bruna J, Herrando M, Navarro X, Udina E. Toxic effects of bortezomib on primary sensory neurons and Schwann cells of adult mice. Neurotox Res. (2015) 27:430-40. doi: 10.1007/s12640-014-9514-8

41. Nicolini G, Monfrini M, Scuteri A. Axonal transport impairment in chemotherapy-induced peripheral neuropathy. Toxics. (2015) 3:322-41. doi: $10.3390 /$ toxics 3030322

42. Staff NP, Podratz JL, Grassner L, Bader M, Paz J, Knight AM, et al. Bortezomib alters microtubule polymerization and axonal transport in rat dorsal root ganglion neurons. Neurotoxicology. (2013) 39:124-31. doi: 10.1016/j.neuro.2013.09.001

43. Kawakami K, Chiba T, Katagiri N, Saduka M, Abe K, Utsunomiya I, et al. Paclitaxel increases high voltage-dependent calcium channel current in dorsal root ganglion neurons of the rat. J Pharmacol Sci. (2012) 120:187-95. doi: 10.1254/jphs.12123FP

44. Jiang Y, Guo C, Vasko MR, Kelley MR. Implications of apurinic/apyrimidinic endonuclease in reactive oxygen signaling response after cisplatin treatment of dorsal root ganglion neurons. Cancer Res. (2008) 68:6425-34. doi: 10.1158/0008-5472.CAN-08-1173

45. Scuteri A, Nicolini G, Miloso M, Bossi M, Cavaletti G, Windebank AJ, et al. Paclitaxel toxicity in post-mitotic dorsal root ganglion (DRG) cells. Anticancer Res. (2006) 26:1065-70.

46. Balboni G, Lazzari I, Trapella C, Negri L, Lattanzi R, Giannini E, et al. Triazine compounds as antagonists at Bv8-prokineticin receptors. J Med Chem. (2008) 51:7635-9. doi: 10.1021/jm800854e

47. Caioli S, Severini C, Ciotti T, Florenzano F, Pimpinella D, Petrocchi Passeri $\mathrm{P}$, et al. Prokineticin system modulation as a new target to counteract the amyloid beta toxicity induced by glutamatergic alterations in an in vitro model of Alzheimer's disease. Neuropharmacology. (2017) 116:82-97. doi: 10.1016/j.neuropharm.2016.12.012

48. Obreja O, Rathee PK, Lips KS, Distler C, Kress M. IL-1 beta potentiates heat-activated currents in rat sensory neurons: involvement of IL-1RI, tyrosine kinase, and protein kinase C. FASEB J. (2002) 16:1497-503. doi: 10.1096/fj.02-0101com

49. Quarta S, Baeumer BE, Scherbakov N, Andratsch M, Rose-John S, Dechant G, et al. Peripheral nerve regeneration and NGF-dependent neurite outgrowth of adult sensory neurons converge on STAT3 phosphorylation downstream of neuropoietic cytokine receptor gp130. J Neurosci. (2014) 34:13222-33. doi: 10.1523/JNEUROSCI.1209-13.2014

50. Quarta S, Mitrić M, Kalpachidou T, Mair N, Schiefermeier-Mach N, Andratsch $\mathrm{M}$, et al. Impaired mechanical, heat, and cold nociception in a murine model of genetic TACE/ADAM17 knockdown. FASEB J. (2019) 33:4418-31. doi: 10.1096/fj.201801901R

51. Meijering E, Jacob M, Sarria JC, Steiner P, Hirling H, Unser M. Design and validation of a tool for neurite tracing and analysis in fluorescence microscopy images. Cytometry Part A. (2004) 58:167-76. doi: 10.1002/cyto.a.20022

52. Fehrenbacher JC. Chemotherapy-induced peripheral neuropathy. Progr Mol Biol Transl Sci. (2015) 131:471-508. doi: 10.1016/bs.pmbts.2014.12.002

53. Qiu CY, Liu YQ, Qiu F, Wu J, Zhou QY, Hu WP. Prokineticin 2 potentiates acid-sensing ion channel activity in rat dorsal root ganglion neurons. $J$ Neuroinflamm. (2012) 9:108. doi: 10.1186/1742-2094-9-108

54. Koyama Y, Kiyo-oka M, Osakada M, Horiguchi N, Shintani $\mathrm{N}$, Ago $\mathrm{Y}$, et al. Expression of prokineticin receptors in mouse cultured astrocytes and involvement in cell proliferation. Brain Res. (2006) 1112:65-9. doi: 10.1016/j.brainres.2006.0 7.013

55. Höke A, Ray M. Rodent models of chemotherapy-induced peripheral neuropathy. ILAR J. (2014) 54:273-81. doi: 10.1093/ilar/ilt053

56. da Silva JS, Dotti CG. Breaking the neuronal sphere: regulation of the actin cytoskeleton in neuritogenesis. Nat Rev Neurosci. (2002) 3:694-704. doi: $10.1038 / \mathrm{nrn} 918$

57. Hui CW, Zhang Y, Herrup K. Non-neuronal cells are required to mediate the effects of neuroinflammation: results from a neuron-enriched culture system. PLoS ONE. (2016) 11:e0147134. doi: 10.1371/journal.pone.0147134

58. Zhou C, Yang A, Chai Z. $\mathrm{Ca}(2+)$ channel currents of cortical neurons from pure and mixed cultures. Cytotechnology. (2012) 64:173-9. doi: 10.1007/s10616-011-9405-2 
59. Ahlemeyer B, Kölker S, Zhu Y, Hoffmann GF, Krieglstein J. Cytosine arabinofuranoside-induced activation of astrocytes increases the susceptibility of neurons to glutamate due to the release of soluble factors. Neurochem Int. (2003) 42:567-81. doi: 10.1016/S0197-0186(02)00164-X

60. Geller HM, Cheng KY, Goldsmith NK, Romero AA, Zhang AL, Morris EJ, et al. Oxidative stress mediates neuronal DNA damage and apoptosis in response to cytosine arabinoside. J Neurochem. (2001) 78:265-75. doi: 10.1046/j.1471-4159.2001.00395.x

61. Malin SA, Davis BM, Molliver DC. Production of dissociated sensory neuron cultures and considerations for their use in studying neuronal function and plasticity. Nat Protoc. (2007) 2:152-60. doi: 10.1038/nprot.2006.461

62. Carozzi VA, Renn CL, Bardini M, Fazio G, Chiorazzi A, Meregalli C, et al. Bortezomib-induced painful peripheral neuropathy: an electrophysiological, behavioral, morphological and mechanistic study in the mouse. PLoS ONE. (2013) 8:e72995. doi: 10.1371/journal.pone.0072995

63. Ustinova EE, Shurin GV, Gutkin DW, Shurin MR. The role of TLR4 in the paclitaxel effects on neuronal growth in vitro. PLoS ONE. (2013) 8:e56886. doi: 10.1371/journal.pone.0056886

64. Qu X, Zhuang G, Yu L, Meng G, Ferrara N. Induction of Bv8 expression by granulocyte colony-stimulating factor in CD11b+Gr1+ cells: key role of Stat 3 signaling. J Biol Chem. (2012) 287:19574-84. doi: 10.1074/jbc.M111.326801

65. Monnier J, Samson M. Cytokine properties of prokineticins. FEBS J. (2008) 275:4014-21. doi: 10.1111/j.1742-4658.2008.06559.x

66. Martucci C, Franchi S, Giannini E, Tian H, Melchiorri P, Negri L, et al. Bv8, the amphibian homologue of the mammalian prokineticins, induces a proinflammatory phenotype of mouse macrophages. Br J Pharmacol. (2006) 147:225-34. doi: 10.1038/sj.bjp.0706467

67. Abou-Hamdan M, Costanza M, Fontana E, Di Dario M, Musio $\mathrm{S}$, Congiu $\mathrm{C}$, et al. Critical role for prokineticin 2 in $\mathrm{CNS}$ autoimmunity. Neurol Neuroimmunol Neuroinflamm. (2015) 2:e95. doi: 10.1212/NXI.0000000000000095

68. Landucci E, Lattanzi R, Gerace E, Scartabelli T, Balboni G, Negri L, et al. Prokineticins are neuroprotective in models of cerebral ischemia and ischemic tolerance in vitro. Neuropharmacology. (2016) 108:39-48. doi: 10.1016/j.neuropharm.2016.04.043

69. Ferrier J, Pereira V, Busserolles J, Authier N, Balayssac D. Emerging trends in understanding chemotherapy-induced peripheral neuropathy. Curr Pain Headache Rep. (2013) 17:364. doi: 10.1007/s11916-013-0364-5

70. Grisold W, Cavaletti G, Windebank AJ. Peripheral neuropathies from chemotherapeutics and targeted agents: diagnosis, treatment, and prevention. Neuro Oncol. (2012) 14 (Suppl. 4):iv45-54. doi: 10.1093/neuonc/nos203

71. Martin DP, Wallace TL, Johnson, EM Jr. Cytosine arabinoside kills postmitotic neurons in a fashion resembling trophic factor deprivation: evidence that a deoxycytidine-dependent process may be required for nerve growth factor signal transduction. J Neurosci. (1990) 10:184-93. doi: 10.1523/JNEUROSCI.10-01-00184.1990

Conflict of Interest: The authors declare that the research was conducted in the absence of any commercial or financial relationships that could be construed as a potential conflict of interest.

Copyright (C) 2020 Moschetti, Kalpachidou, Amodeo, Lattanzi, Sacerdote, Kress and Franchi. This is an open-access article distributed under the terms of the Creative Commons Attribution License (CC BY). The use, distribution or reproduction in other forums is permitted, provided the original author(s) and the copyright owner(s) are credited and that the original publication in this journal is cited, in accordance with accepted academic practice. No use, distribution or reproduction is permitted which does not comply with these terms. 